\title{
ANOVEL ORGANOID MODEL OF IN VITRO SPERMATOGENESIS USING HUMAN INDUCED PLURIPOTENT STEM CELLS
}

\author{
Meghan Robinson ${ }^{1}$, Luke Witherspoon ${ }^{2,3}$, Stephanie Willerth ${ }^{4-6}$, \\ Ryan Flannigan ${ }^{2,7}$
}

\begin{abstract}
${ }^{1}$ Vancouver Prostate Centre, 2660 Oak St, Vancouver, British Columbia, Canada V6H3Z6
${ }^{2}$ Department of Urologic Sciences, University of British Columbia, 2329 West Mall, Vancouver, British Columbia, Canada, V6T1Z4

${ }^{3}$ Department of Urology, The Ottawa Hospital, 501 Smyth R, Ottawa, Ontario, Canada, K1H 8L6

${ }^{4}$ Division of Medical Sciences, University of Victoria, 3800 Finnerty Rd, Victoria, British Columbia, Canada, V8P5C2

${ }^{5}$ Department of Mechanical Engineering, University of Victoria, 3800 Finnerty Rd, Victoria, British Columbia, Canada, V8P5C2

${ }^{6}$ School of Biomedical Engineering, University of British Columbia, Vancouver, British Columbia, Canada

${ }^{7}$ Department of Urology, Weill Cornell Medicine, 1300 York Ave, New York, NY, USA, 10065
\end{abstract}

Author emails

Meghan Robinson: mrobinson@prostatecentre.com; Luke Witherspoon: lwitherspoon@toh.ca;

Stephanie Willerth: willerth@uvic.ca

Corresponding author

Ryan Flannigan, MD

ryan.flannigan@ubc.ca

Phone number: 604-875-5003

Department of Urologic Sciences, University of British Columbia, Vancouver, British Columbia Gordon \& Leslie Diamond Health Care Centre

Level 6, 2775 Laurel Street

Vancouver, BC Canada V5Z 1M9 


\section{Abstract}

Infertility is thought to be caused by genetic mutations and dysfunction in the cellular niche where spermatogenesis takes place. An understanding of the specialized cellular processes which drive spermatogenesis is needed to develop treatments; however, the development of in vitro systems to study these cells has been hindered by our reliance on rarely available human testicular tissues for research. Human induced pluripotent stem cells (hiPSCs) can be used to derive human testicular-like cells, and thus provide an avenue for the development of in vitro testicular model systems. Therefore, this study set out to engineer a human testicular tissue model using hiPSCs for the first time. We demonstrate the ability of hiPSC-derived testicular cells to self-organize and mature into testicular-like tissues using organoid culture. Moreover, we show that hiPSC-derived testicular organoids promote testicular somatic cell maturation and spermatogenesis up to the post-meiotic spermatid stage. These hiPSC-derived testicular organoids have the potential to replace rarely available primary testicular tissues to further infertility research in an in vitro setting.

\section{Key words}

Cell Differentiation, Culture Techniques, Infertility, Spermatogenesis, Testis 


\section{Introduction}

The generation of sperm is a complex process dependent upon the relationships between multiple cell types within the testis.[1] Pinpointing the causes of infertility therefore requires an understanding of the cellular niche where sperm are generated. Advances in single cell sequencing of testicular tissue have begun to shed light on the transcriptomic signatures of the cell types within the niche,[2-8] however the development of in vitro tools to study their interactions and functionalities remains elusive.[9]

Historically, animal models have been the standard in modeling human diseases, however there are specifically human biological processes such as infertility whose complexity and interindividual variability cannot be accurately modeled using animals.[2, 3, 6, 10-15] Consequently, efforts to model infertility have turned to the development of human in vitro systems. One such system that is proving to be a particularly valuable tool for drug discovery, toxicology and personalized medicine is the organoid system.[16] Organoids are 3-dimensional cellular systems that are histologically similar to native tissues and organs, and can recapitulate many of their multicellular processes.[10, 17, 18] They can be generated from pluripotent or multipotent stem cells, and are patterned via the same innate pathways as embryogenesis to form miniature functional units of a larger tissue or organ. Efforts to develop human testicular organoid systems have been significant.[19-24] However, despite success in animal testicular organoid systems, determination of the in vitro conditions necessary for human testicular organoid generation remains a challenge, compounded by the rare accessibility of human testicular tissue for research.[24]

A potential solution is to engineer testicular tissues using human induced pluripotent stem cells (hiPSCs), a Nobel Prize-winning technology pioneered by Shinya Yamanaka in 2007[25] that 
has since revolutionized in vitro modeling and personalized medicine.[26] hiPSCs are adult cells reprogrammed into pluripotent stem cells through the forced expression of a set of key

transcription factors. Like embryonic stem cells, they can give rise to all tissues of the body and regenerate indefinitely, providing an inexhaustible resource for in vitro modeling. Moreover, unlike embryonic stem cells, they can be sourced from a variety of adult cell types, paving the way for personalized medicine.

To date the use of hiPSCs to generate testicular organoids has yet to be investigated, likely because methods for the derivation of the major cellular components of the testicular niche from hiPSCs have only recently been established.[27-30] Using these derivation strategies, we engineered and evaluated a novel model of hiPSC-derived testicular organoids. We assessed their ability to mature and re-organize into testicular-like tissues and support spermatogenesis using immunohistochemical staining techniques and real time quantitative polymerase chain reaction (RT-qPCR) assays. This work reports for the first time the generation of testicular-like tissues from hiPSCs, and demonstrates their potential to model spermatogenesis.

\section{Results}

\section{Cellular identity characterization}

As a first step towards generating testicular organoids we derived the main components of the testicular niche from hiPSCs: Sertoli cells, the main drivers of spermatogenesis; Leydig cells, the producers of testosterone required for Sertoli cell function; endothelial cells, a source of growth factors vital to the homeostasis of the niche; peritubular myoid cells, the contractile smooth muscle cells which facilitate transport of spermatozoa to the epididymis; and spermatogonial stem cells (SSCs), the self-renewing stem cell pool that gives rise to spermatozoa (Figure 1A). The acquisition of testis-specific phenotypes in the hiPSC-derived cells was confirmed by 
immunocytochemistry staining for cell-specific protein expression signatures and markers of maturation (Figure 1B).
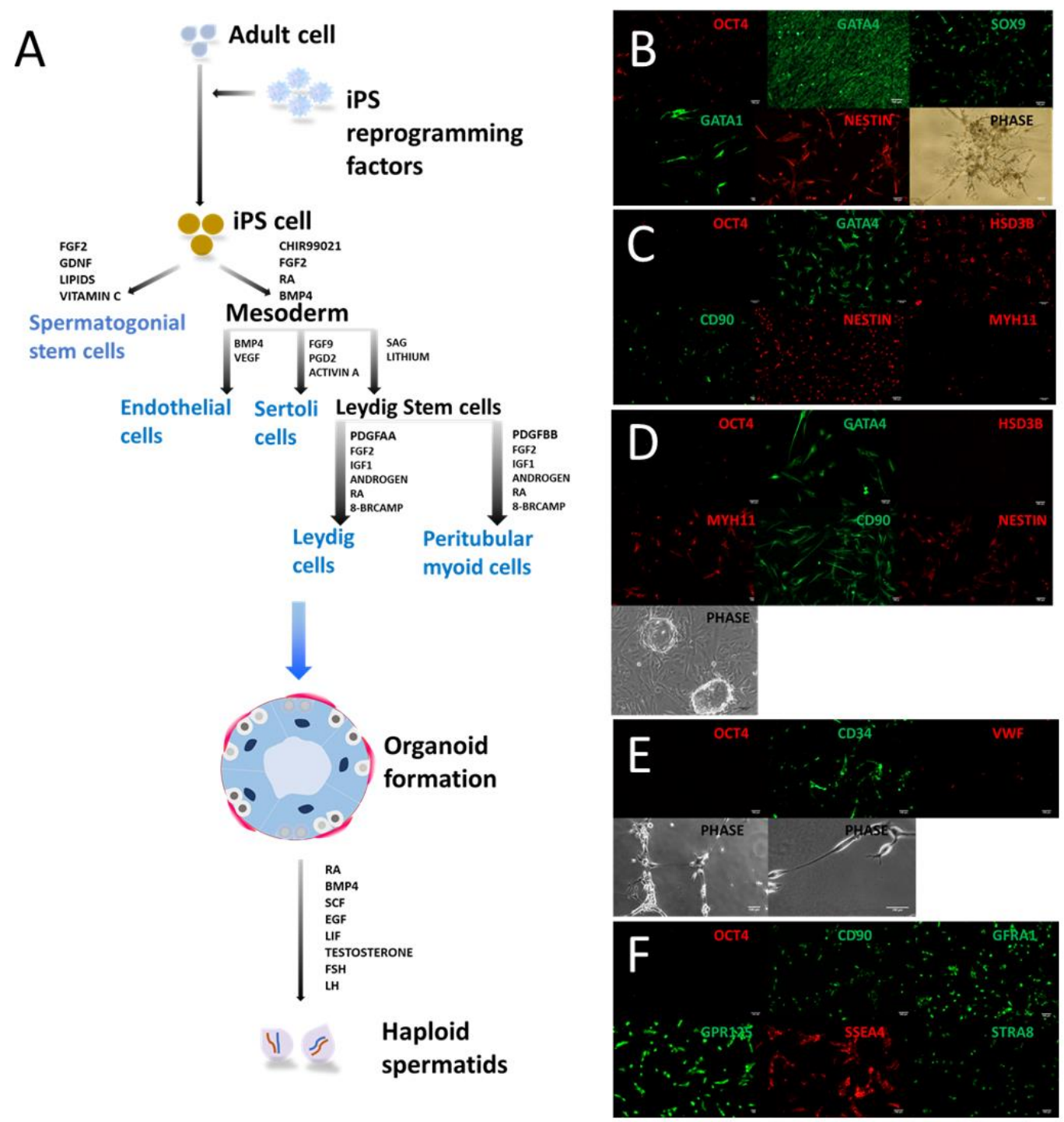

Figure 1. hiPSC derivation of testicular cell types. A) Chart of the derivation of testicular cells from

hiPSCs and organoid culture conditions. B) Immunocytochemistry staining of hiPSC-derived Sertoli cells, and a phase contrast image showing cord formation in 3-D culture. C) Immunocytochemistry staining of hiPSC-derived Leydig cells. D) Immunocytochemistry staining of hiPSC-derived peritubular myoid cells, and a phase contrast image showing ring formation in 2-D culture. E) Immunocytochemistry staining of 


\section{Human stem cell model of spermatogenesis}

hiPSC-derived endothelial cells, and phase contrast images of tubulogenesis in low and high magnifications. F) Immunocytochemistry staining of hiPSC-derived spermatogonial stem cells. All scale bars are $100 \mu \mathrm{m}$. Abbreviations: 8-BRCAMP = 8-bromo-cAMP, BMP4 = Bone Morphogenic Protein 4, CD34 = CD34 Antigen, CD90 $=$ Thy 1 Cell Surface Antigen, EGF $=$ Epidermal Growth Factor, FGF2 = Fibroblast Growth Factor 2, FGF9 = Fibroblast Growth Factor 9, FSH = Follicle Stimulating Hormone, GATA1 = GATA-Binding Protein 1, GATA4 = GATA-Binding Protein 4, GDNF = Glial Cell-Derived Neurotrophic Factor, GFRA1 = GDNF Family Receptor Alpha 1, GPR125 = G-Protein Coupled Receptor 125, HSD3B = Hydroxy-Delta-5-Steroid Dehydrogenase 3 Beta- And Steroid Delta-Isomerase 1, IGF1 = Insulin-Like Growth Factor 1, iPS = induced pluripotent stem, LH = Luteinizing Hormone, LIF = Leukemia Inhibitory Factor, MYH11 = Myosin Heavy Chain 11, OCT4 = Octamer Binding Protein 4, PDGFAA = Platelet-Derived Growth Factor-AA, PDGFBB = Platelet-Derived Growth Factor-BB, PGD2 = Prostaglandin D2, RA = retinoic acid, SAG $=$ smoothened agonist, SCF $=$ Stem Cell Factor, SOX9 $=$ SRY-Box Transcription Factor 9, SSEA4 = Stage-Specific Embryonic Antigen 4, STRA8 = Stimulated By Retinoic Acid 8, VEGF = Vascular Endothelial Growth Factor, VWF = Von Willebrand Factor.

hiPSC-derived Sertoli cells (hSCs) expressed SOX9, a Sertoli cell-specific transcription factor,[31, 32] and GATA4, a testis-specific transcription factor,[33, 34] confirming a Sertoli cell phenotype (Figure 1B). Loss of the pluripotency factor OCT4[35] further confirmed a differentiated status (Figure 1B). However, expression of Nestin, a cytoskeletal filament found in differentiating cells,[36] indicated a state of immaturity (Figure 1B). Confirming this, only a small number of hSCs expressed GATA1, a marker of mature Sertoli cells (Figure 1B).[37] In vivo, immature Sertoli cells form cords which mature during puberty into the seminiferous tubules of the testis,[38] therefore we tested the hSCs for cord-forming functionality by aggregating and seeding them on a 3-dimensional layer of Matrigel[39]. Cords were seen to develop within the Matrigel layer within 24 hours, and became increasingly elongated and 
branched over the course of 7 days, in keeping with an immature Sertoli cell phenotype (Figure 1B).

hiPSC-derived Leydig Cells (hLCs) were negative for the pluripotency factor OCT4, and positive for the testicular marker GATA4 and the differentiation marker Nestin, in keeping with an immature testicular phenotype (Figure 1C). They were also positive for HSD3B, a Leydig cell steroidogenic enzyme required for testosterone synthesis (Figure 1C), confirming Leydig cell character.[40] The mature Leydig cell marker INSL3[40] was negative, while CD90, a Leydig progenitor marker[40, 41], was positive, indicating an immature state (Figure 1C).

hiPSC-derived peritubular myoid cells (hPTMs) were likewise negative for the hiPSC marker OCT4, and positive for the testicular marker GATA4, the progenitor marker CD90, and the differentiation marker Nestin (Figure 1D). Furthermore, hPTMs were positive for peritubular myoid cell marker MYH11[42], confirming their peritubular myoid cell character (Figure 1D). hPTMs were also noted to form ring-like structures in culture, a previously documented characteristic of purified peritubular myoid cell cultures (Figure 1D).[43]

hiPSC-derived endothelial cell (hEC) OCT4 expression was negative as expected, and the endothelial progenitor marker CD34 was positive,[44] confirming vascular differentiation (Figure 1E). VWF, an endothelial cell protein necessary for hemostasis, was only rarely observed by staining, suggesting that the majority of the cells maintained an immature phenotype (Figure 1E).[45] A critical function of endothelial cells is blood vessel formation,[46] so we tested the ability of the hECs to undergo tubulogenesis. After 24 hours in culture on a 3-dimensional layer of Matrigel, hECs formed branching networks of tubular structures as expected (Figure 1E). 
Immunocytochemistry analyses of the hiPSC-derived SSCs (hSSCs) confirmed positive expression of several well-known SSC markers, including CD90, GFRA1, SSEA4, and GPR125,[2, 47, 48] and negative expression for the hiPSC pluripotency factor OCT4 (Figure 1F). Expression of the pre-meiotic stage SSC gene STRA8[49, 50] was also noted (Figure 1F), in keeping with reports of primary SSCs grown in monolayer culture.[20, 21, 51]

\section{hiPSC-derived testicular organoid characterization}

hiPSC-derived testicular cells self-assembled into organoids when cultured overnight in AggreWell ${ }^{\mathrm{TM}} 800$ microwell plates (Figure 2I), and were transferred to non-adherent plates for suspension culture for 12 days (Figure $2 \mathrm{~J}$ ). The culture medium was designed to mimic in vivo conditions through supplementation with hormones FSH, LH and testosterone, to stimulate somatic cell function and maturation, $[52,53]$ and the Sertoli cell-secreted factors BMP4, SCF and retinoic acid, as studies have shown that these factors are required for SSC entry into differentiation.[50, 54-59] The factors EGF and LIF were added for their known effect on promoting viability of SSCs in vitro,[60] and because differentiating germ cells and somatic cells express receptors for these factors in vivo, although reasons for their expression are not well understood.[61-64]

After 12 days in culture, organoids were harvested for gene expression and histochemical analyses. Viability staining was not possible due to high levels of autofluorescence, however the organoids maintained a healthy morphology characterized by a well-defined, bright outer boundary and no visibly dark areas of necrosis (Figure 2J). 

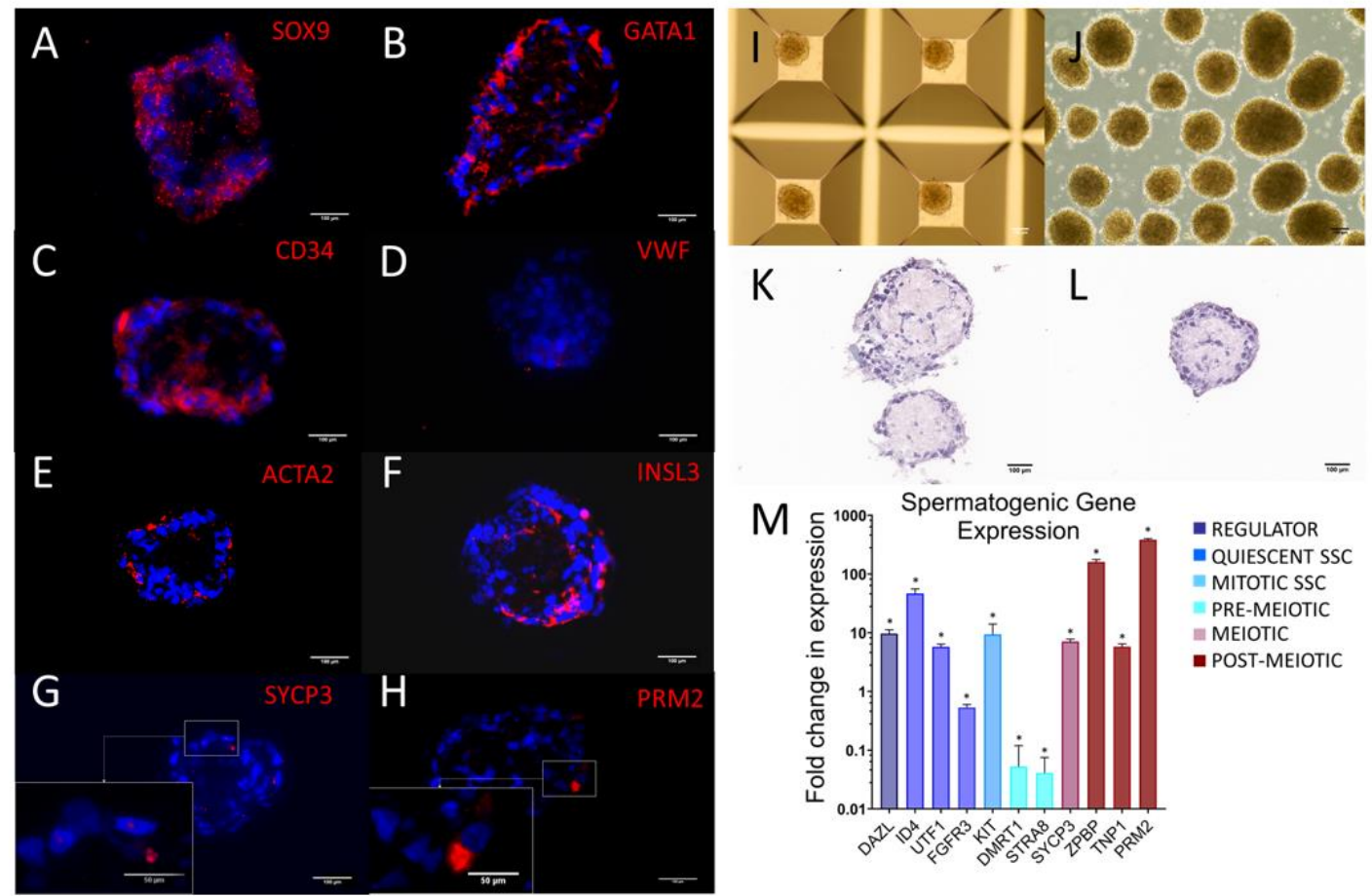

Figure 2. hiPSC-derived testicular organoids. A-H) Immunostaining of organoid sections showing their internal organization and maturation: $\mathrm{SOX9}^{+} / \mathrm{GATA}^{+}=$mature Sertoli cells, $\mathrm{ACTA}^{+}=$peritubular myoid

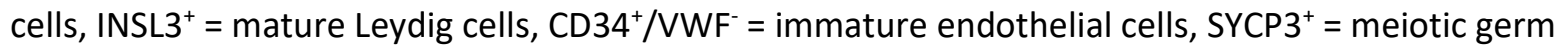
cells, $\mathrm{PRM}^{+}=$post-meiotic germ cells. I) Phase image of organoids 24 hours after formation in microwells. J) Phase image of organoids in suspension culture. K-L) H\&E-stained organoid sections showing the cellular structures. M) Fold change in spermatogenic gene expression of germ cells in the organoids after 12 days (compared to day 0): DAZL is a regulatory gene involved SSC maintenance and differentiation, UTF1, ID4 and FGFR3 are markers of quiescent SSCs, KIT is a marker of mitotic differentiating SSCs, DMRT1 and STRA8 are pre-meiotic markers of early differentiating germ cells, SYCP3 is a marker of meiotic differentiating germ cells, ZPBP, TNP1 and PRM2 are markers of postmeiotic germ cells undergoing spermiogenesis. All scale bars are $100 \mu \mathrm{m}$ except the high magnification SYCP3 and PRM2 images where they are $50 \mu \mathrm{m}$. Abbreviations: ACTA2 = Actin Alpha 2, Smooth Muscle, 
Human stem cell model of spermatogenesis

INSL3 = Insulin-Like 3, CD34 = CD34 Molecule, DAZL = Deleted in Azoospermia-Like, DMRT1 = Doublesex And Mab-3 Related Transcription Factor 1, FGFR3 = Fibroblast Growth Factor Receptor 3, GATA1 = GATA-Binding Protein 1, H\&E = Hematoxylin and Eosin, ID4 = Inhibitor Of DNA Binding 4 HLH Protein, INSL3 = Insulin Like 3, KIT = KIT Proto-Oncogene Receptor Tyrosine Kinase, PRM2 = Protamine 2, SOX9 = SRY-Box Transcription Factor 9, SSC = spermatogonial stem cell, STRA8 = Stimulated By Retinoic Acid 8, SYCP3 = Synaptonemal Complex Protein 3, TNP1 = Transition Protein 1, VWF = Von Willebrand Factor, ZPBP -= Zona Pellucida Binding Protein.

RT-qPCR analysis revealed that the organoids upregulated expression of key genes involved in spermatogenesis (Figure 2M). Expression of DAZL, a master translational regulator vital to SSC self-renewal and differentiation, $[65,66]$ was upregulated 9.7 \pm 1.6 -fold. Accordingly, the quiescent SSC markers UTF1 and ID4[2] also increased 46.7 \pm 8.8-fold and 5.8 \pm 0.6-fold, as did KIT[2, 55], a marker of mitotic differentiating SSCs, by 9.4 \pm 6.7-fold. DMRT1 and STRA8, two retinoic acid-stimulated genes responsible for regulating SSC entry into differentiation,[49, 67-

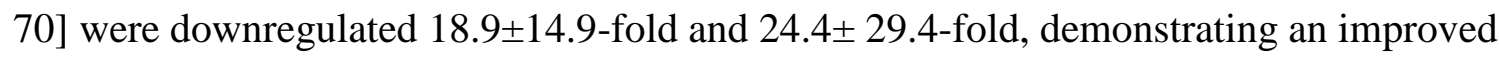
resistance to retinoic acid stimulation over monolayer SSC cultures. Differentiating germ cells reduce their genetic content by half to become haploid spermatids, and to this end they undergo a specialized cell division process termed meiosis, wherein a cell divides twice to generate four genetically different daughter cells, each containing a single set of chromosomes. SYCP3, a marker of meiosis,[2] was upregulated in the organoids 7.1 \pm 0.7 -fold. After completion of meiosis, haploid spermatid cells undergo morphological changes as they mature into final spermatozoa form, characterized by the development of an organelle with egg-penetrating enzymes called an acrosome, head compaction, and elongation of a flagellum structure. ZPBP expression is required for acrosome development,[71] and was seen to increase 160.8 \pm 16.0 -fold, 
while TNP1 and PRM2, two of the genes responsible for head compaction[72], increased

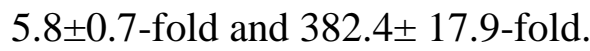

Sectioning and H\&E staining of the organoids revealed tubular internal structures reminiscent of native testicular seminiferous tubule architecture (Figure 2K-L). Immunostaining revealed the tubular structures to be mainly composed of $\mathrm{GATA} 1^{+} / \mathrm{SOX} 9^{+} \mathrm{hSCs}$ and $\mathrm{CD} 34^{+} \mathrm{hECs}$ (Figure 2A-C), while ACTA2 ${ }^{+}$hPTMs and INSL3 ${ }^{+}$hLCs were located near the outer edges of the organoids (Figure 2E-F). Interestingly, the mature Leydig cell marker INSL3 and the mature Sertoli cell marker GATA1 were both highly expressed, indicating that the organoid system had the effect of maturing the hLCs and hSCs. VWF remained negative, suggesting that the hECs did not mature (Figure 2D). SYCP3 ${ }^{+}$meiotic stage differentiating germ cells, and a small number of $\mathrm{PRM}^{+}$post-meiotic stage differentiating germ cells, were noted within the organoids, in agreement with the RT-qPCR analysis (Figure 2G-H).

\section{Discussion}

In this work we derived testicular somatic cells and SSCs from hiPSCs and showed that they spontaneously self-organize into 3-dimensional testicular-like tissues under the right conditions. After 12 days of culture in medium supplemented with hormones and growth factors to mimic the testicular in vivo microenvironment, the organoids matured and began spermatogenesis.

The ability of hiPSC-derived testicular organoids to adopt mature testicular cell phenotypes suggests their use as a surrogate cellular resource for establishing in vitro systems to mature primary human pre-pubertal testicular tissues. Cancer treatments are often gonadotoxic, therefore pre-pubertal patients are given the option of banking their pre-treatment testis tissues[73, 74] however maturing these tissues to generate spermatozoa for in vitro fertilization (IVF) therapies 
remains in the experimental stages, and is currently dependent upon extremely rare pre-pubertal testicular tissues with which to establish in vitro culture systems.[75-77] hiPSC-derived testicular organoids could serve as a suitable alternative resource to optimize such in vitro systems until larger banks of pre-pubertal tissues are available to researchers.

A second important finding was the ability of the hiPSC-derived organoid system to regulate spermatogenesis. In vivo, germ cells exist as a highly heterogeneous population, composed of quiescent, self-renewing and differentiating fractions,[2] and this balance is achieved by short range regulatory paracrine signaling from somatic cells. Self-renewal is stimulated by GDNF signaling, [78-81] while entry into differentiation is controlled by retinoic acid, whose bioavailability is regulated by Sertoli cell-secreted degradative enzymes.[82] Genetic markers for quiescent and self-renewing SSC populations were upregulated in the organoids in parallel with genetic markers of meiotic and post-meiotic stage differentiating germ cells, mirroring in vivolike SSC heterogeneity suggestive of paracrine regulation within the organoids. Indeed, paracrine signaling could explain the noted decrease in retinoic acid-stimulated STRA8 expression in the organoids despite substantially increasing retinoic acid supplementation in the medium. This is in keeping with primary SSC studies showing that SSC resistance to retinoic acid stimulation is contingent on the topography of testis tissue facilitating short range paracrine signaling between specific cell types.[20, 21, 51]

This work illustrates the ability of hiPSCs to generate functional testicular organoids for the first time. We show that testicular somatic cells and SSCs derived from hiPSCs spontaneously organize into miniature tissues that resemble the microarchitecture of native testicular tissue, triggering somatic cell maturation and spermatogenesis. These organoids can serve as a limitless and accessible resource for the study of human testicular tissues in vitro. 


\section{Materials and methods}

\section{hiPSC cell culture}

The hiPSC line used was the 1-DL-01 line from WiCell (hPSCRegID WISCi003-A).[83] hiPSCs

were expanded on Growth Factor Reduced Matrigel (Corning, 354230) in mTeSR TM_Plus

medium (STEMCELL Technologies, $100-0276$ ), at $37^{\circ} \mathrm{C}$ and $5 \% \mathrm{CO}_{2}$, and passaged when $90 \%$ confluent using ReLeSR ${ }^{\mathrm{TM}}$ selective passaging reagent (STEMCELL Technologies, 05872) to maintain purity.

\section{Human ethics}

Experiments using hiPSCs in this study were not subject to ethics approval from the University of British Columbia Research Ethics Boards or Stem Cell Oversight Committee, since they were derived from somatic cells and not intended for transfer into humans or non-human animals.

\section{Differentiation of Leydig cells from hiPSCs}

Leydig cells (hLCs) were differentiated using a previously described method,[28] with a modification. The original protocol yielded $41.5 \%$ Leydig cells, likely because hiPSCs were spontaneously differentiated for 2 days prior to directed differentiation, allowing for endodermal and ectodermal lineage acquisition in addition to mesenchymal. To avoid this, we first directed the hiPSCs towards an intermediate mesenchymal fate using a previously described protocol,[84] wherein cells are treated with 5 MM CHIR99021 (STEMCELL Technologies, 72052) in Roswell Park Memorial Institute Medium 1640 (RPMI 1640, Gibco, 11875-093) for 36 hours, and then 1 $\mu \mathrm{M}$ all-trans retinoic acid (RA, STEMCELL Technologies, 72262) and 100ng/mL human recombinant Fibroblast Growth Factor 2 (FGF2, STEMCELL Technologies, 78003.1) for 2 days. These intermediate mesenchymal cells were then subjected to the protocol for Leydig cell differentiation. Cells were cultured throughout on Matrigel substrates in Dulbecco's Modified Eagle Medium/Nutrient Mixture F-12 with 15mM HEPES (DMEM/F12, STEMCELL 
Technologies , 36254) 1X Insulin Transferrin Selenium Liquid Media Supplement (ITS, Millipore Sigma, I13146), 1\% penicillin/streptomycin (Sigma Aldrich, P4333)and 1X

GlutaMAX (Thermofisher, 35050079), 1\% bovine serum albumin (BSA, Miltenyi Biotec, 130091-376) and $5 \mathrm{ng} / \mathrm{mL}$ luteinizing hormone from human pituitary (LH, Sigma, L6420), with media changes every other day. From 0-7 days, $0.2 \mu \mathrm{M}$ Smoothened Agonist (SAG, STEMCELL Technologies, 73412), $5 \mu \mathrm{M}$ 22R-hydroxycholesterol (22R-OHC, Sigma, H9384), and $5 \mathrm{mM}$ lithium chloride (Sigma, 62476) were added. From 7-10 days, $5 \mathrm{ng} / \mathrm{mL}$ human recombinant Platelet-Derived Growth Factor-AA (PDGF-AA, Peprotech, 100-13A) and $5 \mathrm{ng} / \mathrm{mL}$ FGF2 were added. From 10-17 days, 5 ng/mL PDGF-AA, 5 nM Insulin-Like Growth Factor 1 (IGF1, Peprotech, 100-11), and $10 \mu \mathrm{M}$ testosterone (Toronto Research Chemicals, T155010) were added. From days 17-20, $10 \mathrm{ng} / \mathrm{mL}$ PDGF-AA and $10 \mathrm{ng} / \mathrm{mL}$ FGF2 were added. From days $20-25,5 \mathrm{ng} / \mathrm{mL} \mathrm{LH}$ (total of $10 \mathrm{ng} / \mathrm{mL}$ ), $0.5 \mathrm{mM} \mathrm{RA}$ and $1 \mathrm{mM}$ 8-bromo-cAMP (Peprotech, 2354843) were added. On day 25 cells the cells were switched to Leydig Cell Media (Sciencell Research Laboratories, 4511) for expansion, and passaged onto poly-L-lysine (PLL, Sciencell Research Laboratories, 0413) using TrypLE ${ }^{\mathrm{TM}}$ Express Enzyme (Thermofisher, 12604013).

\section{Differentiation of peritubular myoid cells from hipscs}

hiPSC-derived peritubular myoid cells (hPTMs) were differentiated using the above protocol for hiPSC-derived Leydig cells with the modification that PDGF-AA is replaced by human recombinant Platelet-Derived Growth Factor-BB, as previously described [manuscript submitted] (PDGF-BB, Peprotech, 100-14B). After differentiation, hPTMs were expanded on PLL-coated plates in DMEM/F12, 1X ITS, 1\% penicillin/streptomycin, 2.5\% fetal bovine serum (FBS, Gibco, 12483-020), 10 ng/mL FGF2, 1 ng/mL human recombinant Leukemia Inhibitory 
Factor (LIF, STEMCELL Technologies, 78055.1) and $10 \mathrm{ng} / \mathrm{mL}$ human recombinant Epidermal Growth Factor (EGF, STEMCELL Technologies, 78006.1), and passaged using TrypLETM Express Enzyme.

Differentiation of Sertoli cells from hiPSCs

hiPSC-derived Sertoli cells (hSCs) were differentiated as previously described,[27] but with Matrigel-coated plates instead of feeder cells. hiPSCs were made into embryoid bodies using AggreWell ${ }^{\text {TM}} 800$ microwells (STEMCELL Technologies, 34811) in AggreWell ${ }^{\text {TM }}$ EB Formation Medium (STEMCELL Technologies, 05893), supplemented with 50 ng/mL FGF2 and 30 ng/mL animal-free recombinant human Bone Morphogenic Protein 4 (BMP4, Peprotech, AF-120-05ET) for 24 hours. Embryoid bodies were then transferred to Matrigel-coated plates in DMEM/F12, 1X ITS, $1 \%$ penicillin/streptomycin, 1 X GlutaMAX, $50 \mathrm{ng} / \mathrm{mL}$ recombinant human Fibroblast Growth Factor 9 (FGF9, Peprotech, 100-23), 500 ng/mL Prostaglandin D2 (PGD2, Peprotech 4150768), and $40 \mathrm{ng} / \mathrm{mL}$ animal component-free human recombinant Activin A (STEMCELL Technologies, 78132) for 12 days with media changes every other day. After 12 days the cells were switched to Sertoli Cell Medium (Sciencell, 4521) for expansion, and passaged onto PLLcoated plates using TrypLE ${ }^{\mathrm{TM}}$ Express Enzyme.

\section{Differentiation of endothelial cells from hiPSCS}

hiPSC-derived endothelial cells (hECs) were differentiated as previously described.[85] hiPSCs were subjected to $5 \mu \mathrm{M}$ CHIR99021 in STEMdiff APEL 2 Medium (STEMCELL Technologies, 05270) for 24 hours, followed by $25 \mathrm{ng} / \mathrm{mL}$ BMP4 for 24 hours, and $25 \mathrm{ng} / \mathrm{mL}$ BMP4 with 50 ng/mL human recombinant Vascular Endothelial Growth Factor 165 (VEGF-165, STEMCELL Technologies, 78073) for 2 days. On day 4, 6 million cells were collected and sorted with magnetic activated sorting (MACS), using a PE-conjugated antibody for anti-CD34, the 
EasySep $^{\text {TM }}$ Human PE Positive Selection Kit II (STEMCELL Technologies, 17664), and EasySep $^{\mathrm{TM}}$ Magnet (STEMCELL Technologies, 18000). The purified cells were then expanded on PLL-coated plates in Endothelial Cell Growth Medium (Promocell, C-22010) and passaged using TrypLE ${ }^{\mathrm{TM}}$ Express Enzyme.

\section{Differentiation of SSCs from hiPSCs}

hiPSC-derived SSCs (hSSCs) were differentiated as previously described.[30] hiPSCs were grown on Matrigel in Minimum Essential Medium Alpha (aMEM, Gibco A10490-01), 1X GlutaMAX, 1X ITS, 0.2\% BSA, 1\% penicillin/streptomycin, $1 \mathrm{ng} / \mathrm{mL}$ FGF2, $20 \mathrm{ng} / \mathrm{mL}$ animal component-free human recombinant Glial Cell Derived Neurotrophic Factor (GDNF, STEMCELL Technologies, 78139), 0.2\% Chemically Defined Lipid Concentrate (Thermofisher, 11905031), and $200 \mu \mathrm{g} / \mathrm{mL}$ L-ascorbic acid (Sigma, A4544). Medium was changed every 2 days for 12-15 days. Cells were then switched to expansion medium as previously described, composed of StemPro-34 SFM (Thermofisher, 10639011) supplemented with 1X ITS, $30 \mu \mathrm{g} / \mathrm{ml}$ sodium pyruvate (Sigma, S8636), $1 \mu \mathrm{l} / \mathrm{ml}$ sodium DL-lactic acid solution (Sigma, L4263), 5 mg/ml BSA, 1\% FBS, 1X GlutaMAX, $5 \times 10^{-5}$ M 2-mercaptoethanol (Gibco, 31350-010), 1X Minimal Essential Medium (MEM) Vitamin Solution (Gibco, 11120052), $10^{-4} \mathrm{M}$ ascorbic acid, $10 \mu \mathrm{g} / \mathrm{ml}$ biotin (Sigma, B4639), $30 \mathrm{ng} / \mathrm{ml} \beta$-estradiol (Sigma, E2758), $60 \mathrm{ng} / \mathrm{ml}$ progesterone (Sigma, P8783), 20 ng/mL EGF, 10 ng/mL LIF, and 10 ng/mL GDNF. Cells were passaged onto CellAdhere ${ }^{\mathrm{TM}}$ Laminin-521 coated plates (STEMCELL Technologies, 77004) using TrypLE ${ }^{\mathrm{TM}}$ Express Enzyme (Gibco). 12 million cells were then purified for CD90 ${ }^{+}$cells using a PEconjugated antibody for anti-CD90 (R\&D Systems, FAB2067P), the EasySep ${ }^{\text {TM }}$ Human PE Positive Selection Kit II and EasySep ${ }^{\mathrm{TM}}$ Magnet. 


\section{Generation of organoids}

Testicular organoids were made by mixing hLCs, hSCs, hSSCs, hPTMs and hECs at a 1:2:1:1:1 ratio and placing them into Aggrewell ${ }^{\mathrm{TM}} 800$ microwells overnight. The ratio of hSC to hSSC in the organoids was chosen to be double that observed in vivo (4:1 SC:SSC),[86] to ensure an adequate pool of hSCs, while the remaining somatic cell ratios were approximated by observations of H\&E stained human testicular biopsies. The following day the organoids were transferred to Ultra-Low Adherent Plates for Suspension Culture (STEMCELL Technologies, 38071), at 1 Aggrewell ${ }^{\mathrm{TM}} 800$ well per well (of a 6-well plate), or roughly 300 organoids per well. We cultured organoids throughout in StemPro ${ }^{\text {TM}}-34$ SFM media supplemented with 1X ITS, $30 \mu \mathrm{g} / \mathrm{ml}$ sodium pyruvate, $1 \mu \mathrm{l} / \mathrm{ml}$ DL-lactic acid solution, $5 \mathrm{mg} / \mathrm{ml} \mathrm{BSA,} 1 \% \mathrm{FBS}, 1 \mathrm{X}$ GlutaMAX, $5 \times 10^{-5}$ M 2-mercaptoethanol, 1X MEM Vitamin Solution, $10^{-4}$ M L-ascorbic acid, $10 \mu \mathrm{g} / \mathrm{ml}$ biotin, $30 \mathrm{ng} / \mathrm{ml} \beta$-estradiol, $60 \mathrm{ng} / \mathrm{ml}$ progesterone, $10 \mathrm{ng} / \mathrm{mL} \mathrm{LIF}, 10 \mathrm{ng} / \mathrm{mL}$ EGF, 100 ng/mL Follicle Stimulating Hormone from human pituitary (FSH, Millipore Sigma, F4021), $10 \mathrm{ng} / \mathrm{mL} \mathrm{LH}$, and $1 \mu \mathrm{M}$ metribolone (Toronto Research Chemicals, M338820), $100 \mathrm{ng} / \mathrm{mL}$ BMP4, 100 ng/mL animal-free recombinant human Stem Cell Factor (SCF, Peprotech, AF-30007), and $10 \mu \mathrm{M}$ RA. Each well constituted a single biological replicate in our study.

\section{RT-qPCR}

A sample of $\sim 50$ organoids was taken from each biological replicate and RNA was extracted using an RNeasy Plus Micro Kit (Qiagen, 74034), and checked for integrity using an Agilent 2200 Tapestation System with High Sensitivity RNA Screentape (Agilent, 5067- 5579), High

Sensitivity RNA ScreenTape Sample Buffer (Agilent, 5067- 5580), and High Sensitivity RNA ScreenTape Ladder (Agilent, 5067- 5581). cDNA was generated using iScript ${ }^{\text {TM }}$ Reverse $^{-}$ Transcription Supermix (Bio-Rad, 1708840), followed by pre-amplification with SsoAdvanced ${ }^{\mathrm{TM}}$ PreAmp Supermix (Bio-Rad, 1725160) and pre-amplification primers with a 
Bio-Rad Tetrad2 Peltier Thermal Cycler. RT-qPCR was done with SsoAdvanced ${ }^{\mathrm{TM}}$ Universal SYBR® Green Supermix (Bio-Rad, 1725270) on a LightCycler96 (Roche). Pre-amplification primers and regular primers used were PrimePCR ${ }^{\mathrm{TM}}$ SYBR $®$ Green Assays (Bio-Rad) as listed in Table 1. Technical replicates were carried out in triplicate. Analyses was done in Excel and GraphPad Prism Software. Ct values were normalized to Glyceraldehyde-3-Phosphate Dehydrogenase (GAPDH). Technical replicate outliers were detected using Grubbs' Test, with $\alpha=0.05$. Results of RT-qPCR are presented as the average Relative Quantification (RQ $\left.=2^{-\Delta \Delta C t}\right)$ values and standard deviations of the biological replicates. Any undetected samples were given a Ct value of the maximum detected cycles plus 1 .

\begin{tabular}{|l|l|l|}
\hline \multicolumn{2}{|l|}{ Table 1. Amplicon content sequences and Unique Assay IDs for Bio-Rad PrimePCR } \\
primer pairs used in real time quantitative polymerase chain reaction (RT-qPCR) assays \\
\hline Gene & Amplicon Content Sequence & $\begin{array}{l}\text { Bio-Rad Unique } \\
\text { Assay ID }\end{array}$ \\
\hline DAZL & $\begin{array}{l}\text { GAACATACTGAGTTATAGGATTCATCGTGGTTGTGGGCTGCATATAAGTTTCAGT } \\
\text { GTTTGGATTAGTCCAGACATTCTGAAACTGTGGTGGAGGAGGATGATTAAAAACC }\end{array}$ & qHsaCED0042658 \\
& AAAGGAGGTGG & \\
\hline DDX4 & $\begin{array}{l}\text { TATTCTGGAGAAAATGGAGACAATTTTAACAGGACTCCAGCTTCATCATCAGAAA } \\
\text { TGGATGATGGACCTTCTCGAAGAGATCATTTCATGAAAAGTGGATTTGCCTCTGG } \\
\text { GCGGAATTTTGGAAACAGAGATGCTGGTGAGTGTAATAAGCGAGATAATACATC } \\
\text { CAC }\end{array}$ & qHsaCID0008844 \\
\hline DMRT1 & $\begin{array}{l}\text { GCCCAGTGCGGCCGAGCTGCTTGTCAAAAGAGAGAACAATGGCAGTAACCCGT } \\
\text { GCCTCATGACTGAGTGCAGTGGCACCTCTCAGCCACCGCCGGCCAGTGTCCCC } \\
\text { ACCACTGCAGCTTCAGAGGGACGTATGGTCATCCAGGATATTCCTG }\end{array}$ & qHsaCID0006252 \\
\hline FGFR3 & $\begin{array}{l}\text { TTTATTGAGTTTTTACAAGATGTATTTGTTGTAGACTTAACACTTCTTACGCAAT } \\
\text { GC } \\
\text { TTCTAGAGTTTTATAGCCTGGACTGCTACCTTTCAAAGCTTGGAGGGAAGCCG }\end{array}$ & qHsaCED0042267 \\
\hline
\end{tabular}


bioRxiv preprint doi: https://doi.org/10.1101/2021.06.04.447122; this version posted July 13,2021 . The copyright holder for this preprint (which was not certified by peer review) is the author/funder, who has granted bioRxiv a license to display the preprint in perpetuity. It is made available under aCC-BY-ND 4.0 International license.

Human stem cell model of spermatogenesis

\begin{tabular}{|c|c|c|}
\hline GAPDH & $\begin{array}{l}\text { GTATGACAACGAATTTGGCTACAGCAACAGGGTGGTGGACCTCATGGCCCACAT } \\
\text { GGCCTCCAAGGAGTAAGACCCCTGGACCACCAGCCCCAGCAAGAGCACAAGAG } \\
\text { GAAGAGAGAGACCCTCACTGCTGGGGAGTCCCTGCCACAC }\end{array}$ & qHsaCED0038674 \\
\hline ID4 & $\begin{array}{l}\text { GTTTTGCCCAGTATAGACTCGGAAGTAACAGTTATAGCTAGTGGTCTTGCATGAT } \\
\text { TGCATGAGATGTTTAATCACAAATTAAACTTGTTCTGAGTCCATTCAAATGTGTT } \\
\text { T } \\
\text { TTTTAAATGTAGATT }\end{array}$ & qHsaCED0046882 \\
\hline KIT & $\begin{array}{l}\text { GCGGCGCCTGGGATTTTCTCTGCGTTCTGCTCCTACTGCTTCGCGTCCAGACAG } \\
\text { GCTCTTCTCAACCATCTGTGAGTCCAGGGGAACCGTCTC }\end{array}$ & qHsaCID0008692 \\
\hline PRM2 & $\begin{array}{l}\text { GCCTCCTTCGAGAGCAGTGTCTGCGCCTATAGTGAGACTGGCCATGGGTCCTCT } \\
\text { CGTAGACCTCGACGTGCTCCGGGCTCAGCCCTTGCTCCTCTTGGCCGTGGTGT } \\
\text { CCTTGCTCTTGCCCATGCAACTGCTGCCTGTACACCTCGTGCGAGCGTTCGCTC } \\
\text { AGGCTCCT }\end{array}$ & qHsaCED0002538 \\
\hline STRA8 & $\begin{array}{l}\text { GCTCTTCAACAACCTCAGGAAGACAGTGTACTCTCAGTCTGATCTCATAGCCTCA } \\
\text { AAGTGGCAGGTTCTGAATAAGGCAAAGAGTCATATTCCAGAACTGGAGCAAACC } \\
\text { CTGGATAATTTGCTGAAGC }\end{array}$ & qHsaCID0016584 \\
\hline SYCP3 & $\begin{array}{l}\text { AGTCTTCCCTTCAATAACATCTTCCTCTGATCCACTCAGATCTTTCTTATCTTCAG } \\
\text { TCTCAAAGTCATAGGCTCTCGTAAACTGATCTTCCACAGACGGCTTCCCA }\end{array}$ & qHsaCED0044910 \\
\hline TNP1 & $\begin{array}{l}\text { GCCCTTACGGTATTTTCTTTTGCTGCCACCTCTCTTGACTCCCTTGTGAGGAGAT } \\
\text { CGGCTCTTGCTCCTCCTCATGCCATGACTCTTTAATTTGCGGCTGGTCGACATGG } \\
\text { TAAGTTCTGCCAAAATGAGG }\end{array}$ & qHsaCED0001770 \\
\hline UTF1 & $\begin{array}{l}\text { GCCGCCGCCGCTACAAGTTCCTTAAAGACAAGTTTCGCGAGGCGCACGGCCAG } \\
\text { CCGCCCGGGCCCTTCGACGAGCAGATCCGGAAGCTCATG }\end{array}$ & qHsaCED0046843 \\
\hline $\mathrm{ZPBP}$ & $\begin{array}{l}\text { CTTAAGTAAGGAAATTTCACATGAAAGGTCAAGAAGCAGTTTGCTTAAAATCTGA } \\
\text { AGAAGTTTCTTCTCAAAAGAAATATTATAAATGCTATTGCAGGGAGCTGCATGAT } \\
\text { A } \\
\text { TCGAGCTGTGAACTGATAATAATAATGAGGCTCACGATA }\end{array}$ & qHsaCED0042089 \\
\hline \multicolumn{3}{|c|}{$\begin{array}{l}\text { Abbreviations: DAZL = Deleted in Azoospermia-Like, DDX4 = DEAD-Box Helicase 4, DMRT1 = } \\
\text { Doublesex And Mab-3 Related Transcription Factor 1, FGFR3 = Fibroblast Growth Factor } \\
\text { Receptor 3, GAPDH = Glyceraldehyde-3-Phosphate Dehydrogenase , ID4 = Inhibitor Of DNA } \\
\text { Binding } 4 \text { HLH Protein, KIT = KIT Proto-Oncogene, Receptor Tyrosine Kinase, PRM2 = Protamine } \\
\text { 2, STRA8 = Stimulated by Retinoic Acid 8, SYCP3 = Synaptonemal Complex Protein 3, TNP1 = }\end{array}$} \\
\hline
\end{tabular}


Human stem cell model of spermatogenesis

Transition Protein 1, UTF1 = Undifferentiated Embryonic Cell Transcription Factor 1, ZPBP = Zona Pellucida Binding Protein.

Table 1. Amplicon content sequences (amplicon sequence with additional base pairs added to the beginning and/or end of the sequence), and Unique Assay IDs for Bio-Rad PrimePCR ${ }^{\mathrm{TM}}$ primer pairs used.

\section{Immunocytochemistry}

Cells were fixed for 15 minutes in $4 \%$ paraformaldehyde solution (PFA, Thermo Scientific,

J19943-K2), permeabilized for 15 minutes in 0.1\% Triton X-100 (Sigma, X100) in phosphate

buffered saline (PBS), and blocked for 2 hours in 5\% normal goat serum (NGS, Abcam, ab7481)

in PBS. Primary antibodies were diluted in PBS as follows: anti-Hydroxy-Delta-5-Steroid

Dehydrogenase, 3 Beta- And Steroid Delta-Isomerase 1 (HSD3 $\beta$, Novus Biologicals, NB110-

7844) 1:200, anti-Myosin Heavy Chain 11 (MYH11, Abcam, ab212660) 1:1000, anti-Octamer

Binding-Protein 4 (OCT4, Abcam, ab184665) 1:500, anti-SRY-Box Transcription Factor 9

(SOX9, Abcam, ab76997) 1:500, anti-GATA Binding Protein 4 (GATA4, Abcam, ab84593)

1:100, anti-Nestin (Millipore, MAB5326) 1:200, anti-Thy-1 Cell Surface Antigen (THY1/CD90, Abcam, ab133350) 1:200, anti-GATA Binding Protein 1 (GATA1, Abcam, ab28839) 1:300, anti-Insulin Like 3 (INSL3, Novus Biologicals, NBP1-81223) 1:500, anti-CD34 Molecule (CD34, Abcam, ab81289) 1:250, anti-Von Willebrand Factor (VWF, Invitrogen, MA5-14029)

1:100, anti-GDNF Family Receptor Alpha 1 (GFRA1, Abcam, ab84106) 1:200, anti-Stagespecific embryonic antigen-4 (SSEA4, Abcam ab16287) 1:300, anti-G Protein-Coupled Receptor 125 (GPR125, Abcam, ab51705) 1:200, anti-Vimentin (Abcam, ab20346) 1:1000, anti-STRA8 (Millipore ABN1656) 1:100, and incubated overnight at $4^{\circ} \mathrm{C}$ in the dark. Cells were rinsed 3 times with PBS for 15 minutes each at $4{ }^{\circ} \mathrm{C}$ in the dark. Goat anti-Rabbit $\operatorname{IgG}(\mathrm{H}+\mathrm{L})$ Highly Cross-Adsorbed Secondary Antibody Alexa Fluor 488 (Thermofisher, A-11034) or Goat antiMouse IgG (H+L) Highly Cross-Adsorbed Secondary Antibody Alexa Fluor 568 (Thermofisher, 
A-11031) were diluted 1:200 in PBS and incubated with the cells for 4 hours at $4{ }^{\circ} \mathrm{C}$ in the dark.

Cells were rinsed another 3 times with PBS for 15 minutes each at $4^{\circ} \mathrm{C}$ in the dark. $4^{\prime}, 6$ -

diamidino-2-phenylindole (DAPI, Abcam, ab228549) was diluted to $2.5 \mu \mathrm{M}$ in PBS and added

to the cells for 15 minutes in the dark at room temperature, and then replaced by PBS. Cells were imaged using a Zeiss AXio Observer microscope equipped with laser excitation and fluorescence filters for AlexaFluor 488, AlexaFluor 568 and DAPI, and images were processed using ZEN Blue and ImageJ software.

\section{Immunofluorescence staining of 3-D organoids}

Sectioning and immunofluorescent staining of the organoids was done as described

previously,[87] with some modifications. The remaining $~ 250$ organoids from each biological replicate were fixed for 24 hours in $4 \%$ PFA solution, followed by 24 hours in $30 \%$ sucrose

(Sigma, S1888) solution in PBS. The organoids were then re-suspended in $0.5 \mathrm{~mL} 7.5 \%$ gelatin from porcine skin (Sigma, G2500) with 10\% sucrose in PBS and incubated at $37^{\circ} \mathrm{C}$ for 1 hour to allow the gelatin to penetrate the organoids before they were gently pipetted into $10 \times 10 \times 5 \mathrm{~mm}$ cryomolds (Tissue-Tek, 4565) and flash frozen. Flash frozen samples were then cut into $6 \mu \mathrm{m}$ sections using a cryostat with the block temperature set to $-30^{\circ} \mathrm{C}$, and placed onto Superfrost Plus microscope slides (Fisherbrand, 22-037-246). A hydrophobic barrier was drawn around the tissue sections using a hydrophobic PAP pen (Abcam, ab2601), and the sections were incubated with $0.1 \%$ Tween 20 (Sigma, P1379) in PBS at $37^{\circ} \mathrm{C}$ for 10 minutes to dissolve the gelatin solution. Sections were blocked for 1 hour with 5\% NGS in $0.1 \%$ Tween 20 in PBS in a humidity chamber at room temperature. Primary antibodies were diluted in $0.1 \%$ Tween 20 in PBS with 0.05\% sodium azide and 5\% Bovine Serum Albumin (BSA) as follows: 1:300 antiGATA1, 1:500 anti-Actin Alpha 2, Smooth Muscle (ACTA2, Thermofisher, 14-9760-82), 1:500 
anti-INSL3, and 1:300 anti-SYCP3 (Novus Biologicals, NB300-232). Sections were incubated in the diluted primary antibodies overnight in a humidity chamber at room temperature. The following day the sections were rinsed 3 times with $0.1 \%$ Tween 20 in PBS for 30 minutes each in a humidity chamber, followed by incubation for 2 hours in Goat anti-Mouse $\operatorname{IgG}(\mathrm{H}+\mathrm{L})$ CrossAdsorbed Secondary Antibody Alexa Fluor 647 (Thermofisher, A-21235) or Goat anti-Rabbit IgG (H+L) Cross-Adsorbed Secondary Antibody Alexa Fluor 647 (Thermofisher, A27040) diluted 1:2000 in 0.1\% Tween 20 in PBS. We used only Alexa Fluor 647 because we noted the organoids to auto-fluoresce in the $488 \mathrm{~nm}$ and $568 \mathrm{~nm}$ wavelengths, but not in the $647 \mathrm{~nm}$ wavelength. The sections were then rinsed 3 more times for 30 minutes each with $0.1 \%$ Tween 20 in PBS, with the final rinse containing $2.5 \mu \mathrm{M}$ DAPI. Sections were imaged immediately using a Zeiss AXio Observer microscope equipped with laser excitation and fluorescence filters for AlexaFluor 647 and DAPI, and images were processed using ZEN Blue and ImageJ software.

\section{Hematoxlyin and Eosin (H\&E) staining}

Embedding and sectioning was completed as described in Immunofluorescence staining. After sectioning, a hydrophobic barrier was drawn around the tissue sections using a hydrophobic PAP pen, and they were incubated with $0.1 \%$ Tween 20 in PBS for 10 minutes at $37^{\circ} \mathrm{C}$ to dissolve the gelatin solution. The slides were then placed in hematoxylin solution (Sigma Aldrich, MHS32) for 3 minutes, followed by tap water for 1 minute 2 times in separate containers, $0.1 \%$ sodium bicarbonate (Sigma S5761) solution for 1 minute, tap water for 1 minute, $95 \%$ ethanol for 1 minute, Eosin Y reagent (Sigma Aldrich, HT110216) for 1 minute, 95\% ethanol for 1 minute, 100\% ethanol for 1 minute 2 times in separate containers, and 3 minutes in xylene (Fisher Scientific X5-500). 1-2 drops of CytoSeal mounting media (Thermofisher, 8312-4) was placed on each slide, a coverslip was placed on top, and the slides were allowed to dry overnight in a 
fume hood. The organoids were imaged using an Olympus BX-UCB from PerkinElmer Life

Sciences and VECTRA system.

\section{Statistical analysis}

Statistics were performed using GraphPad Prism software. Each experiment was performed in biological triplicate, and in the case of RT-qPCR, in technical triplicate as well. Significance between groups was determined by comparing $\Delta \mathrm{Ct}$ values using a student's unpaired two-tailed t-test, with $\alpha=0.05$. The standard deviations between biological replicates are represented by error bars in the figures, and statistically significant differences between groups is denoted by * in the figures.

\section{Glossary}

\author{
differentiating \\ endothelial cells \\ gonadotoxic \\ haploid \\ human induced pluripotent stem cells
}

in vitro

in vitro fertilization (IVF)

in vivo

Leydig cells
A term for the process of stem cell development into specialized cell types.

Endothelial cells form the barrier between vessels and tissue and control the flow of substances and fluid into and out of a tissue.

Gonadotoxicity is the temporary or permanent damage to ovaries or testes after exposure to certain substances or drugs Haploid is the quality of a cell having a single set of chromosomes.

iPSC are derived from skin or blood cells that have been reprogrammed back into an embryonic-like pluripotent state that enables the development of an unlimited source of any type of human cell needed for therapeutic purposes.

Outside of the body, typically referring to a laboratory setting

In vitro fertilization (IVF) is a method of assisted reproduction that involves the removal of eggs from the body, and the combining of eggs and sperm in the embryology laboratory to form embryos. The resulting embryos can then be placed into the uterus in the hopes of achieving a pregnancy.

Within the body

Leydig cells, also known as interstitial cells of Leydig, are found adjacent to the seminiferous tubules in the testicle. They produce testosterone in the presence of luteinizing hormone (LH) 
Matrigel

meiosis

organoid

paracrine signaling

peritubular myoid cells

personalized medicine

quiescent

Sertoli cells

spermatid

spermatogenesis

spermatogonial stem cells

tissue banking
Matrigel is the trade name for a gelatinous protein mixture secreted by Engelbreth-Holm-Swarm (EHS) mouse sarcoma cells produced by Corning Life Sciences.

Meiosis is a process where a single cell divides twice to produce four cells containing half the original amount of genetic information.

An organoid is a miniaturized and simplified version of an organ produced in vitro in three dimensions that shows realistic micro-anatomy. They are derived from one or a few cells from a tissue, embryonic stem cells or induced pluripotent stem cells, which can self-organize in three-dimensional culture owing to their self-renewal and differentiation capacities.

Paracrine signaling is a form of cell signaling, a type of cellular communication in which a cell produces a signal to induce changes in nearby cells, altering the behaviour of those cells.

A peritubular myoid cell is one of the smooth muscle cells which surround the seminiferous tubules in the testis.

Personalized medicine, also referred to as precision medicine, is a medical model that separates people into different groupswith medical decisions, practices, interventions and/or products being tailored to the individual patient based on their predicted response or risk of disease

A term for "reserve" pools of stem cells that in a state of inactivity or dormancy.

A Sertoli cell (a kind of sustentacular cell) is a "nurse" cell of the testicles that is part of a seminiferous tubule and helps in the process of spermatogenesis, the production of sperm. It is activated by follicle-stimulating hormone (FSH) secreted by the adenohypophysis, and has FSH receptor on its membranes

The spermatid is the haploid male gametid that results from division of secondary spermatocytes.

Spermatogenesis is the process by which haploid spermatozoa develop from spermatogonial stem cells in the seminiferous tubules of the testis

A spermatogonial stem cell, also known as a type A spermatogonium, is a spermatogonium that does not differentiate into a sperm cell. Instead, they continue dividing into other spermatogonia or remain dormant to maintain a reserve of spermatogonia.

The process of cryopreserving tissues for long-term storage and viability. 


\section{Acknowledgements}

The authors would like to acknowledge the Vancouver Prostate Centre for their financial support, and the Lange Lab at the Vancouver Prostate Centre for their technical support.

\section{Conflict of Interest}

None.

\section{References}

[1] Chen H, Mruk D, Xiao X, Cheng CY. Human Spermatogenesis and Its Regulation. In: Winters SJ, Huhtaniemi IT, editors. Male Hypogonadism: Basic, Clinical and Therapeutic Principles. Cham: Springer International Publishing; 2017. p. 49-72.

[2] Guo J, Grow EJ, Mlcochova H, Maher GJ, Lindskog C, Nie X, et al. The adult human testis transcriptional cell atlas. Cell Res. 2018;28:1141-57.

[3] Guo J, Nie X, Giebler M, Mlcochova H, Wang Y, Grow EJ, et al. The Dynamic Transcriptional Cell Atlas of Testis Development during Human Puberty. Cell Stem Cell. 2020;26:262-76 e4.

[4] Wu X, Lu M, Yun D, Gao S, Chen S, Hu L, et al. Single cell ATAC-Seq reveals cell type-specific transcriptional regulation and unique chromatin accessibility in human spermatogenesis. Hum Mol Genet. 2021.

[5] Hermann BP, Cheng K, Singh A, Roa-De La Cruz L, Mutoji KN, Chen IC, et al. The Mammalian Spermatogenesis Single-Cell Transcriptome, from Spermatogonial Stem Cells to Spermatids. Cell Rep. 2018;25:1650-67 e8.

[6] Shami AN, Zheng X, Munyoki SK, Ma Q, Manske GL, Green CD, et al. Single-Cell RNA Sequencing of Human, Macaque, and Mouse Testes Uncovers Conserved and Divergent Features of Mammalian Spermatogenesis.

Dev Cell. 2020;54:529-47 e12.

[7] Tan K, Song HW, Wilkinson MF. Single-cell RNAseq analysis of testicular germ and somatic cell development during the perinatal period. Development. 2020;147.

[8] Zhao L, Yao C, Xing X, Jing T, Li P, Zhu Z, et al. Single-cell analysis of developing and azoospermia human testicles reveals central role of Sertoli cells. Nat Commun. 2020;11:5683.

[9] Komeya M, Sato T, Ogawa T. In vitro spermatogenesis: A century-long research journey, still half way around. Reprod Med Biol. 2018;17:407-20.

[10] Kim J, Koo BK, Knoblich JA. Human organoids: model systems for human biology and medicine. Nat Rev Mol Cell Biol. 2020;21:571-84.

[11] Working PK. Male Reproductive Toxicology - Comparison of the Human to Animal-Models. Environ Health Persp. 1988;77:37-44.

[12] Miyamoto T, Tsujimura A, Miyagawa Y, Koh E, Namiki M, Sengoku K. Male Infertility and Its Causes in Human. Advances in Urology. 2012;2012:384520.

[13] Miyamoto T, Minase G, Shin T, Ueda H, Okada H, Sengoku K. Human male infertility and its genetic causes. Reproductive Medicine and Biology. 2017;16:81-8.

[14] Bennett A. The Use of Human Tissues and Cells in Biomedical Research: The Unusual Suspects. AtlaAltern Lab Anim. 2010;38:5-9.

[15] Zietek T, Giesbertz P, Ewers M, Reichart F, Weinmuller M, Urbauer E, et al. Organoids to Study Intestinal Nutrient Transport, Drug Uptake and Metabolism - Update to the Human Model and Expansion of Applications. Front Bioeng Biotechnol. 2020;8:577656.

[16] Takahashi T. Organoids for Drug Discovery and Personalized Medicine. Annu Rev Pharmacol Toxicol. 2019;59:447-62.

[17] Merrell AJ, Stanger B. Adult cell plasticity in vivo: de-differentiation and transdifferentiation are back in style. Nat Rev Mol Cell Bio. 2016;17:413-25. 
Human stem cell model of spermatogenesis

[18] Fatehullah A, Tan SH, Barker N. Organoids as an in vitro model of human development and disease. Nat Cell Biol. 2016;18:246-54.

[19] Alves-Lopes JP, Stukenborg JB. Testicular organoids: a new model to study the testicular microenvironment in vitro? Hum Reprod Update. 2018;24:176-91.

[20] Sakib S, Goldsmith T, Voigt A, Dobrinski I. Testicular organoids to study cell-cell interactions in the mammalian testis. Andrology. 2020;8:835-41.

[21] Sakib S, Voigt A, Goldsmith T, Dobrinski I. Three-dimensional testicular organoids as novel in vitro models of testicular biology and toxicology. Environ Epigenetics. 2019;5.

[22] von Kopylow K, Schulze W, Salzbrunn A, Schaks M, Schafer E, Roth B, et al. Dynamics, ultrastructure and gene expression of human in vitro organized testis cells from testicular sperm extraction biopsies. Mol Hum Reprod. 2018;24:123-34.

[23] Oliver E, Stukenborg JB. Rebuilding the human testis in vitro. Andrology. 2020;8:825-34.

[24] Richer G, Baert Y, Goossens E. In-vitro spermatogenesis through testis modelling: Toward the generation of testicular organoids. Andrology. 2020;8:879-91.

[25] Takahashi K, Tanabe K, Ohnuki M, Narita M, Ichisaka T, Tomoda K, et al. Induction of pluripotent stem cells from adult human fibroblasts by defined factors. Cell. 2007;131:861-72.

[26] Yamanaka S. Induced pluripotent stem cells: past, present, and future. Cell Stem Cell. 2012;10:678-84.

[27] Rodriguez Gutierrez D, Eid W, Biason-Lauber A. A Human Gonadal Cell Model From Induced Pluripotent Stem Cells. Front Genet. 2018;9:498.

[28] Chen X, Li C, Chen Y, Xi H, Zhao S, Ma L, et al. Differentiation of human induced pluripotent stem cells into Leydig-like cells with molecular compounds. Cell Death Dis. 2019;10:220.

[29] Williams IM, Wu JC. Generation of Endothelial Cells From Human Pluripotent Stem Cells. Arterioscler Thromb Vasc Biol. 2019;39:1317-29.

[30] Zhao YC, Ye SC, Liang DL, Wang PX, Fu J, Ma Q, et al. In Vitro Modeling of Human Germ Cell Development Using Pluripotent Stem Cells. Stem Cell Rep. 2018;10:509-23.

[31] Chui K, Trivedi A, Cheng CY, Cherbavaz DB, Dazin PF, Huynh AL, et al. Characterization and functionality of proliferative human Sertoli cells. Cell Transplant. 2011;20:619-35.

[32] Hemendinger RA, Gores P, Blacksten L, Harley V, Halberstadt C. Identification of a specific Sertoli cell marker, Sox9, for use in transplantation. Cell Transplant. 2002;11:499-505.

[33] Ketola I, Pentikainen V, Vaskivuo T, Ilvesmaki V, Herva R, Dunkel L, et al. Expression of transcription factor GATA-4 during human testicular development and disease. J Clin Endocrinol Metab. 2000;85:3925-31.

[34] Viger RS, Mertineit C, Trasler JM, Nemer M. Transcription factor GATA-4 is expressed in a sexually dimorphic pattern during mouse gonadal development and is a potent activator of the Mullerian inhibiting substance promoter. Development. 1998;125:2665-75.

[35] Pan GJ, Chang ZY, Scholer HR, Pei DQ. Stem cell pluripotency and transcription factor Oct4. Cell Research. 2002;12:321-9.

[36] Bernal A, Arranz L. Nestin-expressing progenitor cells: function, identity and therapeutic implications. Cell Mol Life Sci. 2018;75:2177-95.

[37] Yomogida K, Ohtani H, Harigae H, Ito E, Nishimune Y, Engel JD, et al. Developmental Stage-Specific and Spermatogenic Cycle-Specific Expression of Transcription Factor Gata-1 in Mouse Sertoli Cells. Development. 1994;120:1759-66.

[38] Cool J, DeFalco T, Capel B. Testis formation in the fetal mouse: dynamic and complex de novo tubulogenesis. Wires Dev Biol. 2012;1:847-59.

[39] Gassei K, Ehmcke J, Schlatt S. Initiation of testicular tubulogenesis is controlled by neurotrophic tyrosine receptor kinases in a three-dimensional Sertoli cell aggregation assay. Reproduction. 2008;136:459-69.

[40] Ye L, Li X, Li L, Chen H, Ge RS. Insights into the Development of the Adult Leydig Cell Lineage from Stem Leydig Cells. Front Physiol. 2017;8:430.

[41] Chen P, Zirkin BR, Chen H. Stem Leydig Cells in the Adult Testis: Characterization, Regulation and Potential Applications. Endocr Rev. 2020;41.

[42] Mayerhofer A. Human testicular peritubular cells: more than meets the eye. Reproduction. 2013;145:R107-16.

[43] Mishra J, Gautam M, Dadhich R, Kowtharapu BS, Majumdar SS. Peritubular cells may modulate Leydig cell-mediated testosterone production through a nonclassic pathway. Fertil Steril. 2012;98:1308-17 e1. [44] Sidney LE, Branch MJ, Dunphy SE, Dua HS, Hopkinson A. Concise Review: Evidence for CD34 as a Common Marker for Diverse Progenitors. Stem Cells. 2014;32:1380-9. 
Human stem cell model of spermatogenesis

[45] Tiemeier GL, de Koning R, Wang G, Kostidis S, Rietjens RGJ, Sol W, et al. Lowering the increased intracellular $\mathrm{pH}$ of human-induced pluripotent stem cell-derived endothelial cells induces formation of mature Weibel-Palade bodies. Stem Cells Transl Med. 2020;9:758-72.

[46] Xu K, Cleaver O. Tubulogenesis during blood vessel formation. Seminars in Cell \& Developmental Biology. 2011;22:993-1004.

[47] Conrad S, Azizi H, Hatami M, Kubista M, Bonin M, Hennenlotter J, et al. Differential gene expression profiling of enriched human spermatogonia after short- and long-term culture. Biomed Res Int.

2014;2014:138350.

[48] Altman E, Yango P, Moustafa R, Smith JF, Klatsky PC, Tran ND. Characterization of human spermatogonial stem cell markers in fetal, pediatric, and adult testicular tissues. Reproduction. 2014;148:417-27.

[49] Ma HT, Niu CM, Xia J, Shen XY, Xia MM, Hu YQ, et al. Stimulated by retinoic acid gene 8 (Stra8) plays important roles in many stages of spermatogenesis. Asian Journal of Andrology. 2018;20:479-87.

[50] Hogarth CA, Griswold MD. The key role of vitamin A in spermatogenesis. J Clin Invest. 2010;120:956-62.

[51] Lord T, Oatley MJ, Oatley JM. Testicular Architecture Is Critical for Mediation of Retinoic Acid

Responsiveness by Undifferentiated Spermatogonial Subtypes in the Mouse. Stem Cell Rep. 2018;10:538-52.

[52] Sofikitis N, Giotitsas N, Tsounapi P, Baltogiannis D, Giannakis D, Pardalidis N. Hormonal regulation of spermatogenesis and spermiogenesis. J Steroid Biochem Mol Biol. 2008;109:323-30.

[53] Koskenniemi JJ, Virtanen HE, Toppari J. Testicular growth and development in puberty. Curr Opin Endocrinol. 2017;24:215-24.

[54] Yang YG, Feng YM, Feng X, Liao SY, Wang XX, Gan HY, et al. BMP4 Cooperates with Retinoic Acid to Induce the Expression of Differentiation Markers in Cultured Mouse Spermatogonia. Stem Cells Int. 2016;2016.

[55] Mauduit C, Hamamah S, Benahmed M. Stem cell factor/c-kit system in spermatogenesis. Hum Reprod Update. 1999;5:535-45.

[56] Yan W, Suominen J, Toppari J. Stem cell factor protects germ cells from apoptosis in vitro. J Cell Sci. 2000;113:161-8.

[57] Vernet N, Dennefeld C, Rochette-Egly C, Oulad-Abdelghani M, Chambon P, Ghyselinck NB, et al. Retinoic acid metabolism and signaling pathways in the adult and developing mouse testis. Endocrinology.

2006;147:96-110.

[58] Law SM. Retinoic Acid Receptor Alpha in Germ Cells is Important for Mitosis of Spermatogonia, Spermatogonial Differentiation and Meiosis. Washington State, USA: Washington State University; 2013.

[59] Hasegawa K, Saga Y. Retinoic acid signaling in Sertoli cells regulates organization of the blood-testis barrier through cyclical changes in gene expression. Development. 2012;139:4347-55.

[60] Sadri-Ardekani H, Mizrak SC, van Daalen SK, Korver CM, Roepers-Gajadien HL, Koruji M, et al. Propagation of human spermatogonial stem cells in vitro. JAMA. 2009;302:2127-34.

[61] Shiraishi K, Matsuyama H. Local Expression of Epidermal Growth Factor-Like Growth Factors in Human Testis and Its Role in Spermatogenesis. J Androl. 2011;33:66-73.

[62] Yan YC, Sun YP, Zhang ML, Koide SS. Testis epidermal growth factor and spermatogenesis. Arch Andrology. 1998;40:133-46.

[63] Curley M, Milne L, Smith S, Atanassova N, Rebourcet D, Darbey A, et al. Leukemia Inhibitory FactorReceptor is Dispensable for Prenatal Testis Development but is Required in Sertoli cells for Normal Spermatogenesis in Mice. Sci Rep-Uk. 2018;8.

[64] Jenab S, Morris PL. Testicular leukemia inhibitory factor (LIF) and LIF receptor mediate phosphorylation of signal transducers and activators of transcription (STAT)-3 and STAT- 1 and induce c-fos transcription and activator protein-1 activation in rat Sertoli but not germ cells. Endocrinology. 1998;139:1883-90.

[65] Li HX, Liang ZQ, Yang J, Wang D, Wang HB, Zhu MY, et al. DAZL is a master translational regulator of murine spermatogenesis. Natl Sci Rev. 2019;6:455-68.

[66] Zagore LL, Sweet TJ, Hannigan MM, Weyn-Vanhentenryck SM, Jobava R, Hatzoglou M, et al. DAZL Regulates Germ Cell Survival through a Network of PolyA-Proximal mRNA Interactions. Cell Rep. 2018;25:1225-+.

[67] Don J, Nir U, Breitbart H. DMRT1 at the border between mitosis and meiosis. Asian Journal of Andrology. 2011;13:189-90.

[68] Gerhardt K. Multifaceted DMRT1 Reveals Additional Roles in Spermatogenesis. Biol Reprod. 2016;95:111. 
Human stem cell model of spermatogenesis

[69] Matson CK, Murphy MW, Griswold MD, Yoshida S, Bardwell VJ, Zarkower D. The Mammalian Doublesex Homolog DMRT1 Is a Transcriptional Gatekeeper that Controls the Mitosis versus Meiosis Decision in Male Germ Cells. Developmental Cell. 2010;19:612-24.

[70] Zhang T, Zarkower D. DMRT proteins and coordination of mammalian spermatogenesis. Stem Cell Res. 2017;24:195-202.

[71] Lin YN, Roy A, Yan W, Burns KH, Matzuk MM. Loss of zona pellucida binding proteins in the acrosomal matrix disrupts acrosome biogenesis and sperm morphogenesis. Mol Cell Biol. 2007;27:6794-805.

[72] Waclawska A, Kurpisz M. Key functional genes of spermatogenesis identified by microarray analysis. Syst Biol Reprod Med. 2012;58:229-35.

[73] David BA, Plat G, Cartault A, Bouali O. Puberty Development and Testicular Growth after Cryoconservation in Prepubertal Boys Facing Gonatotoxic Therapy. Pediatr Blood Cancer. 2019;66:S520-S1. [74] Goossens E, Jahnukainen K, Mitchell RT, van Pelt A, Pennings G, Rives N, et al. Fertility preservation in boys: recent developments and new insights (dagger). Hum Reprod Open. 2020;2020:hoaa016.

[75] de Michele F, Poels J, Weerens L, Petit C, Evrard Z, Ambroise J, et al. Preserved seminiferous tubule integrity with spermatogonial survival and induction of Sertoli and Leydig cell maturation after long-term organotypic culture of prepubertal human testicular tissue. Hum Reprod. 2017;32:32-45.

[76] Giudice MG, de Michele F, Poels J, Vermeulen M, Wyns C. Update on fertility restoration from prepubertal spermatogonial stem cells: How far are we from clinical practice? Stem Cell Res. 2017;21:171-7.

[77] Huleihel M, Lunenfeld E. Approaches and Technologies in Male Fertility Preservation. Int J Mol Sci.

2020;21.

[78] Chen LY, Willis WD, Eddy EM. Targeting the Gdnf Gene in peritubular myoid cells disrupts

undifferentiated spermatogonial cell development. Proc Natl Acad Sci U S A. 2016;113:1829-34.

[79] Kubota H, Wu X, Goodyear SM, Avarbock MR, Brinster RL. Glial cell line-derived neurotrophic factor and endothelial cells promote self-renewal of rabbit germ cells with spermatogonial stem cell properties. Faseb J. 2011;25:2604-14.

[80] Sharma M, Braun RE. Cyclical expression of GDNF is required for spermatogonial stem cell homeostasis. Development. 2018;145.

[81] Spinnler K, Kohn FM, Schwarzer U, Mayerhofer A. Glial cell line-derived neurotrophic factor is constitutively produced by human testicular peritubular cells and may contribute to the spermatogonial stem cell niche in man. Hum Reprod. 2010;25:2181-7.

[82] Feng CW, Bowles J, Koopman P. Control of mammalian germ cell entry into meiosis. Mol Cell Endocrinol. 2014;382:488-97.

[83] WiCell. iPS(Foreskin)-1. WiCell; 2021.

[84] Lam AQ, Freedman BS, Morizane R, Lerou PH, Valerius MT, Bonventre JV. Rapid and efficient differentiation of human pluripotent stem cells into intermediate mesoderm that forms tubules expressing kidney proximal tubular markers. J Am Soc Nephrol. 2014;25:1211-25.

[85] Tan JY, Sriram G, Rufaihah AJ, Neoh KG, Cao T. Efficient derivation of lateral plate and paraxial mesoderm subtypes from human embryonic stem cells through GSKi-mediated differentiation. Stem Cells Dev. 2013;22:1893-906.

[86] Hikim APS, Chakraborty J, Jhunjhunwala JS. Germ-Cell Quantitation in Human Testicular Biopsy. Urol Res. 1985;13:111-5.

[87] Technologies S. Cryogenic Tissue Processing and Section Immunofluorescence of Cerebral Organoids. Stemcell Technologies; 2019. p. Document \#27171. 